\title{
El oficio de antropólogo. Crítica de la razón (inter)cultural de José Sánchez Parga
}

Germán Carrillo García

\begin{abstract}
En cierto modo la visión inventada por el Partido se imponía con excelente éxito a la gente incapaz de comprenderla. Hacia aceptar las violaciones más flagrantes de la realidad, porque nadie comprendía del todo la enormidad de lo que se les exigía, ni se interesaba lo suficiente por los acontecimientos públicos para darse cuenta de lo que ocurría. Por falta de comprensión, todos eran políticamente sanos y fieles.

Sencillamente, se lo tragaban todo.
\end{abstract}

1984, George Orwell.

La cita introductoria de la obra de Orwell, es casi una declaración programática de las dificultades que atraviesa cualquier investigador, especialmente desde las Ciencias Sociales, para comprender la confusa realidad en la actual sociedad de mercado.

El oficio de antropólogo. Crítica de la razón (Inter) cultural, de Sánchez Parga es una dilucidante obra que ante la obviedad plantea dudas; en la 'deshistorización' (como apuntó Bourdieu) plantea el ejercicio complejo de historizar $\mathrm{y}$, con ello, profundizar en las causas que provocan los hechos sociales a través de un péndulo que oscila entre disciplinas y conocimientos que abarcan el psicoanálisis, la causística histórica, la lingüística, la filosofía, entre otras, siempre desde la atalaya epistemológica y metodológica -en constante revisión- de la antropología. Esta interpelación científica es, más que necesaria, imperativa para comprender los fenómenos culturales porque, como señala el autor, citando a Marcel Mauss: "las grandes ondas de la civilización vienen de muy lejos y llegan también muy lejos". Así, desde esta visión crítica, radical y holística, el autor trasciende el propio oficio de antropólogo y lo solapa al de humanista.

Ser antropólogo requiere de sólidas bases intelectuales, ante todo porque es la ciencia que estudia al hombre, siendo "la antropología una práctica del sujeto, que comienza planteándose un conocimiento del 'otro' (la otra cultura) para terminar planteándose en un conocimiento de sí mismo (la propia cultura) a partir del otro" (p. 15). Se requiere, pues, de un ejercicio psicoanalítico para despojarse de la panoplia interior de los prejuicios, incrustados, sin saberlo, en el inconsciente. Precisa, este oficio, una especial sensibilidad hacia lo humano. 
La mirada antropológica es también una mirada prístina, un reencuentro con el inconsciente colectivo del presente y del pasado.

La estructura de la obra presentada deviene en un itinerario lógico que comienza con la conceptualización de la 'diferencia', elemento clave para entender el oficio de antropólogo. Sánchez Parga plantea una cita de Hegel que, a priori, explica todo el capítulo primero: "Diferente no es más que ser para otro". "Sin embargo, la diferencia no es una realidad ni un dato, ni siquiera una cualidad realmente existente en la otra cultura, sino más bien una categoría producto de una relación, de una comparación, y sin existencia real al margen de dicha relación" (p. 19). De esta forma planteada la diferencia cultural, se entienden otras categorías, como la supuesta novedad, que algunos presuponen de la Interculturalidad. La presunción es la de manipular dicho concepto como un elemento aislado del de cultura, como un proceso del presente ahistórico, incurriendo en un grave error, puesto que cualquier cultura es intercultural por el propio proceso histórico de las formaciones culturales de la sociedad humana, ya que "todos los pueblos son sociológicamente iguales, la diferencia es cultural" (p. 24). En este devenir comprensivo de la diferencia, la antropología ha sufrido un proceso epistemológico y metodológico que comenzó con el llamado descubrimiento de América.

En este primer acercamiento al 'otro', a las 'sociedades salvajes', existe una negación de la condición humana de ese 'otro'; prejuicio no exclusivo de los europeos, ya que las sociedades tradicionales también establecen ese mismo tratamiento conceptual para con los 'otros' pueblos. La paradoja, y a pesar de este tránsito de la evolución epistemológica de la antropología, radica en que en plena actualidad y, tal vez más que nunca, se anatemiza al 'otro', a toda alteridad, como el enemigo o el invasor, que transcurre en paralelo con una obsesión identitaria, donde identidad y alteridad se vuelven antagónicas. “¿No será que la profunda crisis de identidad característica de la sociedad moderna ha conducido a una búsqueda desenfrenada de identidades y a las más diversas ilusiones identitarias? se pregunta J. Sánchez Parga (p. 299). Volvemos a los postulados del buen salvaje, a una "reconfiguración del racismo (...) donde la noción de raza es sustituida por la de etnia o cultura; substitución de la idea de pureza racial por la de identidad cultural; se escamotea la idea de desigualdad, encubriéndola por la de diferencia (...) evitando contactos para preservar las 
identidades diferenciadas" (p. 302); dando lugar a una multitud de identidades imaginadas a través de la 'invención de la tradición', que escribió Hobsbawm. Otra paradoja en medio de un mundo llamado global, que tiende más al clash de civilizaciones a lo Huntington, que al encuentro con la alteridad; choque fomentado a través de políticas públicas y acciones pseudoacadémicas que practican una interculturalidad administrativa o de gestión.

En un segundo momento del desarrollo teórico de la ciencia antropológica, la alteridad se representa "como déficits y limitaciones. Se trataría de pueblos que (...) no han evolucionado culturalmente al haberse quedado inmóviles o retrasados en sus orígenes (...) se opera ya una forma de apropiarse e identificarse con el 'otro', de reconocerse en él en cuanto origen del propio pasado cultural" (p. 22), aunque más tarde, estos mismos pueblos primitivos son asociados a la categoría de subdesarrollados. Tanto el calificativo de primitivo dio lugar a la colonización y evangelización de dichos pueblos así tildados, como posteriormente "la idea del otro como subdesarrollado daría lugar a un evolucionismo desarrollista en lo económico". Y en la actualidad, para la sociedad de mercado, la diferencia supone una asimilación a lo occidental a través de políticas de integración que abarcan desde el multiculturalismo a la asimilación cultural, con denominadores en común todas ellas: identidad contra alteridad, exclusión y marginalidad, y todo un drama de 'interculturalidad utilitarista'.

No obstante, el antropólogo debe hacer frente a estos fenómenos excluyentes de la alteridad a través de reconocerse en ella misma, 'ser' en el otro. O como bien señala J. Sánchez Parga a través de Laplantine "no hay en efecto antropología sin intercambio" (p. 36); como no hay cultura que no tenga en su desarrollo histórico y presente un proceso intercultural. Así, el antropólogo no puede ser irreflexivo y ver la diferencia cultural como un fenómeno desintegrador, sino como elemento cultural relacional. Un claro ejemplo que propone el autor en la p. 358 y que es de plena actualidad hace referencia al velo de las mujeres musulmanas el cual, nunca antes del 11 de septiembre de 2001 había constituido "un problema o impedimento para su integración a las sociedades europeas; hoy se ha convertido en una intolerable obsesión (...) el presunto objetivo de la prohibición para mejor integrar a la mujer musulmana tendrá más bien efectos opuestos no sólo entre la mujer sino en toda la sociedad". Es aquí y ahora donde el oficio de antropólogo se hace más urgente, ante los miedos que 
causan no tanto las diferencias sino las propias similitudes, como magníficamente ha argumentado el autor. Miedos y prejuicios, productos consustanciales a la carencia de conocimientos.

Pero todo este proceso iniciático de El oficio de antropólogo que da lugar a la reflexividad para comprender y trascender lo aparente a lo causal, comienza con "la iniciación o el viaje antropológico" título con que José Sánchez Parga nombra el Capítulo II; el viaje como ritual, el viaje como símbolo (LéviSrauss). "En este sentido la iniciación del antropólogo se muestra análoga a la del psicoanalista: sólo quien ha sido analizante, puede convertirse en analista, pues únicamente quien ha hecho la experiencia de la propia neurosis, quien se ha confrontado con ese otro interior y diferente, con ese desconocido que es su inconsciente, puede ejercer en cuanto psicoanalista. Esta analogía se prolonga entre el trabajo del psicoanalista y el de antropólogo (...), el trabajo antropológico consiste en un continuo y progresivo reconocimiento de la otra cultura (...) hasta descubrir que la diferencia de la otra cultura está en mi propia cultura" (p. 48), presupuesto capital sin el cual el antropólogo no se consolida como tal, y tan sólo será un instrumento gestor o administrativo de 'lo cultural'.

Pero para reconocerse en la otra cultura se precisa un trabajo de campo antropológico, y no se trata de un cronotopo determinado, sino más bien supone 'una disposición particular en su modo de investigar' (p. 67). Es aquí donde J. Sánchez Parga plantea cuestiones esenciales para una correcta investigación de campo, es decir no limitarse a la comprensión verbal, sino también al conocimiento de los códigos: una especie de lectura entre líneas, un acercamiento a través de la reflexividad observante. Cita el autor en la página 70: "El trabajo de campo es ante todo un itinerario interior, epistemológico, por el cual el antropólogo sale de sus tópicos para dejarse penetrar por otra topología”. Es a raíz de esta interpretación de la tarea de investigación en campo que el autor prosigue manifestando la catarsis o metamorfosis, que el aprendiz debe sufrir para comprender la alteridad, incluso la propia metodología ha de estructurarse en estos términos: "cuanto más desarmado de instrumentos y artefactos metodológicos (...) mejor se predispone para observar no tanto lo que había planificado sino lo que surge y aparece (...) no para preguntar de acuerdo a unos previos intereses investigativos, que quizás no sean los más interesantes, sino para mirar y escuchar" (p. 72). Y aunque la antropología sea cada 
vez más at home, ello no presupone un abandono de esta propuesta mirada epistemológica y metodológica. De hecho, el antropólogo tiene un interesante campo de trabajo y desarrollo de investigaciones en la antropología urbana sin abandonar los significantes de la antropología clásica. Así por ejemplo, propone Sánchez Parga en su libro, el estudio de las crisis etarias o 'complejo de umbral', un drama de desubicación donde el adolescente o el anciano no saben donde empieza y acaba su etapa vital, su tránsito hacia el siguiente umbral del desarrollo humano, su rito de pasaje. En este caso, el antropólogo conocedor de los ritos de pasaje de las sociedades tradicionales, podrá explicar las crisis etarias mencionadas en la sociedad moderna, en otros términos, el antropólogo es un psicoanalista de la cultura.

Pero es aquella sensibilidad antropológica, elemento clave de la empatía para con el 'otro', la que supone un ejercicio vital que empieza con el viaje, la iniciación antropológica y continúa $-\mathrm{y}$ nunca acaba- con la Observación (Cap.IV), siendo ésta la que realmente define el método antropológico, más aún que la entrevista o el cuestionario. Pero no una observación exterior, sino una averiguación interior sobre la externalidad. "Hay que observar muy de cerca las diferencias entre culturas, para comprender la lógica y unidad de la cultura humana" (p. 93); citando a Rousseau el autor ratifica la argumentación anterior: "observar las diferencias para descubrir las propiedades". Y sin embargo, es la observación, como método antropológico el más infravalorado, posiblemente ante las carencias mismas de variables cuantificables o de una estructura ponderable. Igualmente ocurre con la entrevista donde se dimensiona, a veces, más las variables medibles y aparentes que la propia hermenéutica de la palabra, que trasciende en lo simbólico, que explica los significantes a través de las cosmovisiones culturales, tanto del que entrevista como del entrevistado.

$\mathrm{Y}$ es que, en general las ciencias sociales, y la antropología en particular, en muchos casos han adoptado criterios metodológicos y epistemológicos más afines con una 'administración o gestión social y cultural', que con una generación teórica de conocimiento, o dicho con otras palabras: se ha buscado la aplicabilidad antes que la propia teorización. Ante esta situación se pregunta J. Sánchez Parga en el Capítulo IX ¿son aplicables las ciencias sociales? Supone ésta una cuestión capital y de actualidad. La mercantilización del academicismo ha supuesto una reducción de las "Ciencias Sociales a sus funciones más 
utilitarias, descriptivas, calculadoras y cuantificadoras sobre los hechos sociales, con la única finalidad de dar recetas, modelos de intervención más o menos ineficaces o contraproducentes (...) se trata de someter la razón teórica de las Ciencias Sociales a la razón administrativa" (pp. 245-246). Con estos posicionamientos se incurren en fallas imponderables ya que se obvia totalmente la causística que provoca los hechos sociales. Se detrimenta la investigación teórica en aras de una supuesta acción que muy alejada del conocimiento científico, se acerca a presupuestos administrativos: "buscar aplicaciones no debe ser el objeto ni el fin de la ciencia, eso supondría falsear ésta", así lo manifiesta el autor a través de Marcel Mauss. En definitiva, "no basta con decorar la acción o las intervenciones sociales, las aplicaciones con muchas ideas" (p. 248) para garantizar la eficacia de dichas intervenciones. "Hay que distinguir ciencia de la acción” (p. 249). En consonancia con esta posición son muchas las críticas que se han hecho a esta patología pseudocientífica. Hoy más que nunca las 'luchas contra la pobreza' o contra cualquier otro corolario, son paradigmáticas de este sentido orientativo de las Ciencias Sociales. Así, magistralmente, J. Sánchez Parga argumenta: "La explicación es obvia, no luchando contra la pobreza sino contra sus causas se puede reducirla o terminar con ella. Pero estas causas son precisamente lo más difícil de intervenir: el modelo de producción, acumulación, y concentración de riqueza en el mundo" (p. 259). Sin investigar en un sentido profundo, generando conocimiento científico, no se podrán resolver los susodichos problemas que produce la sociedad de mercado.

Es un déficit de la sociedad moderna la pérdida de la memoria histórica como elemento de base para la comprensión del presente. Más no obstante, la antropología al igual que el psicoanálisis, requieren de una 'teoría del olvido' (p. 149), de una entrada al inconsciente cultural donde además adquieren verdadero sentido las prácticas culturales. Esta interrelación entre las teorías freudianas y la antropología, es expuesta en el Capítulo VI: "La escucha entre cultura e inconsciente", donde adquiere gran relevancia la antropología estructuralista de Lévi-Strauss, el cual define cultura como "la naturaleza inconsciente de los fenómenos colectivos". En este sentido, la antropología utiliza la escucha, no como una simple entrada de significantes, sino otorgando un sentido psicoanalítico. El paralelismo entre ambas ciencias es evidente: para el psicoanálisis el 'otro' es el inconsciente al que hay que atraer al 'yo' consciente; para la antropología, el 
'otro' es la alteridad pero, “sólo desde la subjetividad del 'otro' en cuanto 'yo', puede el antropólogo llegar a comprender y explicar la otra cultura” (pp. 157158). Así es como existe una deuda entre ambas ciencias, hecho manifestado por C. Lévi-Strauss cuando hace alusión precisamente a que "son las conductas en apariencia más afectivas, las operaciones menos racionales, las manifestaciones declaradas prelógicas, que son al mismo tiempo las más significantes” (p. 163).

En definitiva, José Sánchez Parga en un ejercicio que podría decirse hermenéutico, adentra al lector en el sentido profundo de la epistemología antropológica y, más aún, de las Ciencias Sociales. Exponiendo como la 'realidad latente', a la que hacía alusión Ortega y Gasset, ha de ser atraída hacia la superficie, dando de esta forma, explicación a los hechos sociales. Así 'La metáfora del iceberg' refleja con claridad la necesidad de atraer a línea de flotación el inconsciente cultural, que es además donde se hallan los elementos comunes de todas las culturas. Pero este viaje antropológico hacia la averiguación de lo común en las culturas, se vuelve camino pedregoso y no exento de dificultades.

En el Capítulo VII "Las historias y los tiempos de la antropología" el autor subraya la cadencia del tiempo en las sociedades tradicionales, donde el pasado está inmerso en el presente, suponiendo una especie de 'amnesia de futuro'; por contra, las sociedades modernas han hecho del presente el futuro, "viviendo cada vez más proyectadas hacia el porvenir" (p. 195). Esto conlleva una doble interpretación: por un lado, el antropólogo ha de relativizar los tiempos y las culturas para entender las cronologías y las acciones, sin caer en el etnocentrismo (tan de vuelta) de "proyectar las vivencias y mensuraciones temporales en la otra cultura", afirma Lévi-Strauss. Por otro lado, esta aceleración de los tiempos en la sociedad moderna, este vivir en el futuro, constituye un handicap para el antropólogo poco preparado: éste va a ver únicamente la línea del iceberg patente, dejando lo común, lo profundo bajo la línea de flotación. Es un error al que se incurre muy a menudo - de forma consciente o no- al prejuzgar los ritos culturales de sociedades no-occidentales como actos 'primitivos' con un sentido peyorativo, como por ejemplo, la panoplia árabe o el culto musulmán; o el mismo tempo vital del indígena andino. Por ello, como bien apunta J. Sánchez Parga, es fundamental, no sólo para la antropología, sino para todo conocimiento científico, la elaboración de un método intercultural, hacer del investigador un problema y ser consciente del inconsciente, lo que supone un 
doble ejercicio intelectual y espiritual: generar conocimientos y ser sensible a todo fenómeno cultural.

Pero si la nueva 'razón cultural' es la 'razón de mercado', donde la cultura es devastada por el mismo capital, así como éste devasta el conocimiento, como argumentó C. Marx, donde "lo que no es rentable y convertible en mercancía, lo que se sustrae a la oferta y demanda o al valor de cambio, será desechable y eliminado" (p. 394), entonces, ¿qué lugar hay para la antropología en una sociedad que denota la reflexivilidad sobre los hechos sociales? ¿Qué lugar hay para el 'otro' en la preeminencia del narcisismo y etnocentrismo de la sociedad de mercado? ¿Qué lugar ocupa la alteridad en la inmediatez de la noticia, 'en el directo', 'en la devastación de la inteligencia' a través de una sociedad que hace de la tecnología su gurú intelectual? En conclusión, se interroga el autor a través de Touraine, ¿Podremos vivir juntos. Iguales y diferentes? Las respuestas a esta cuestión capital, que supone además el gran reto de una sociedad denominada global, vienen determinadas por el nivel de conocimientos, rigor científico, y grado de sensibilidad que el ser humano vaya adquiriendo a lo largo de su desarrollo vital. Ya se ha dicho que los prejuicios suponen un dique para la razón intercultural, pero además los prejuicios son producto del desconocimiento y de la negación de la alteridad, de la negación del reconocimiento en el 'otro' de mi propio 'yo'. Pero los dilemas ante los que se enfrenta la antropología son graves: "así aparece hoy el intercambio antropológico, fundador de sentido y de diferencia culturales, atenazado por el terrible dilema del mercado y la guerra. Pero no cualquier guerra, sino la guerra terrorista y antiterrorista (...) siendo despojado de toda alteridad el terrorista ya no es un enemigo al que se puede vencer o hacer la paz, sino alguien a quien no cabe más que liquidar". Con estos planteamientos muy en desintonía con postulados acríticos o asépticos, José Sánchez Parga ha sido capaz de argumentar científicamente la deriva de la modernidad hacia un mundo que agoniza como escribió el vallisoletano Miguel Delibes.

La obra recensionada constituye un estudio científico de primer orden, tanto para estudiosos de la antropología como para disciplinas afines. Es más, el libro de José Sánchez Parga es -a mi juicio- un ejercicio intelectual que indaga en el sentido profundo de los hechos culturales y sociales, dando posibles respuestas a través de revisiones y aportaciones epistemológicas y metodológicas que van más allá de la obviedad y de la realidad aparente. 